\title{
NOTAS MICOLOGICAS: Hortaea werneckii EN AMBIENTES SALINOS DEL NORTE CHILENO
}

\author{
(Mycological notes: Hortaea werneckii in saline environment \\ in northern Chile)
}

\author{
E. Piontelli, L.*, M.A. Grixolli, A.* \\ C. Riquelme, S. ** \& M.Jorquera,T.** \\ *Universidad de Valparaíso, Escuela de Medicina \\ Cátedra de Micología, Casilla 92 V. Valparaíso, Chile. \\ **Universidad de Antofagasta, Fac. de Recursos del Mar \\ Av. Jaime Guzmán s/n. Casilla 170, Antofagasta, Chile.
}

Palabras clave: Hortaea werneckii, ambiente salino, moluscos.

Key words: Hortaea werneckii, saline environment, mollusc.

\section{RESUMEN}

Mediante determinaciones morfológicas y fisiológicas, se describe el primer aislamiento del hongo dematiáceo levaduriforme Hortaea werneckii en agua de mar y moluscos del norte chileno( Antofagasta, II Región).

Se comenta al mismo tiempo junto a los aportes de la literatura, algunos datos ecológicos, epidemiológicos y taxonómicos de esta levadura negra.

\section{INTRODUCCION}

Debido al escaso aislamiento de levaduras negras desde ambientes acuáticos, telúricos o material clínico, su hallazgo es siempre un motivo de interés para el microbiólogo.

Como comenta De Hoog \& McGinnis (1987), estos microorganismos, no se consideran nomalmente en los textos de taxonomía de levaduras, debido a la presencia de melanina en sus paredes y a la frecuente capacidad de formar sinanamorfos miceliales, y por ende, presentar un comportamiento ecológico diferente a la mayoría de las levaduras. Los ciclos de vida de algunas especies consideradas como levaduras negras, pueden presentar varias fases (polimorfismo), pero en general, son inicialmente higrofílicas, con predominio de formas levadurilormes gemantes (de rápido crecimiento en medios licjuidos) y posteriormente higrofóbicas, con formación de hifas que producen conidios lejos del sustrato, permitiendo su dispersión aérea. Este pleoanamorlismo se considera como

\section{SUMMARY}

Trough morphological and physiological determinations, the first isolation of dematiaceous yeast-like fungus Hortaea werneckii in sea water and of molluscis in northern Chile (Antofagasta, II Region) is described.

Besides the contributions of literature, some ecological, epidemiological and taxonomical information about this black yeast is also given.

una adaptación genética que le otorga fuertes ventajas ecológicas, pero complica para el micólogo médico la delimitación de las especies de este grupo.

En los últimos 2 decenios, con el empleo de técnicas moleculares, la literatura de las llamadas levaduras negras, ha presentado fuertes cambios taxonómicos, desde el variable concepto de morlo especie, basado en criterios conidiogénicos (De Hoog, 1977; Cole 1978), hacia el más estable de especie filogenética (Uitjthof et al., 1993; Haase et al., 1995; Masclaux et al., 1995).

McGinnis et al. (1992), define a una levadura negra como un hongo dematiạceo, de morfología simple, que se presenta como una célula solitaria, gemante, que durante parte de su ciclo de vida, funciona como un conidióforo reducido. Algunas especies no son capaces de producir hilas (Phaeococcomyces nigricans (Rich \& Stem) de Hoog), mientras otras como Placoanellomyces elegans McGimnis \& Shell, presentan a menudo en los cultivos viejos, un sinanamorfo hifomicetoso asociado (Exophiala jeanselmei (Langeron ) McGinnis \& Padhye). 
Debe recalcarse que a pesar que casi todas las levaduras negras se presentan como unicelulares, Phaeoanellomyces werneckii, (Horta) McGinnis \& Shell, se caracteriza por ser bicelular.

Hortaea werneckii (Horta) Nishimura \& Miyaji, también conocida en la literatura bajo el nombre de Exophiala werneckii (Horta) von Arx, Phaeoanellomyces werneckii, (Horta) McGinnis \& Shell o Cladosporium werneckii Horta (consulte McGinnis et al., 1985, para todos los sinónimos), es un Ascomycete polimórfico con un sistema de coenzima Q (Takeo \& De Hoog, 1991), pero carente en su pared celular de la estructura lamelar típica de los Basidiomycetes (Kreger van Rij \& Veenhius , 1970). Esta levadura se encuentra principalmente compitiendo como saprotrofa en diversos ambientes con altas concentraciones salinas, tales como agua de mar y las arenas de playas (Moket al.,1981; Matte deet al., 1986,1988; De Cock, 1994). Pero su mayor importancia radica en que se considera como un agente etiológico de tinea nigra palmaris (faeohifomicosis) en el hombre, una infección asintomática, generalmente limitada a las superlicies palmares o plantares (Rippon, 1988). La mayor casuística de esta enfermedad se describe en la literatura micológica de los paises tropicales o sub tropicales, especialmente en Sudamerica (Borelli, 1977; Fischman, et al., 1983; Conti-Diazet al.,1984: Cordero et al., 1985, Severo et al., 1994). Sin embargo, en Chile no se ha descrito su aislamiento, ni existen referencias de cuadros clínicos. La única relación con esta enfermedad, es un caso en la literatura brasilera, donde se afirma su adquisición en Chile (Severo et al., 1994).

Los objetivos de esta nota son : comentar junto a los aportes de la literatura, algunos datos ecológicos, morfológicos, fisiológicos y taxonómicos de esta levadura.

\section{MATERIALES Y METODOS}

\section{Biogeografía y obtención de las cepas.}

Investigando el posible uso de varias levaduras marinas en los cultivos de moluscos bivalvos en el norte chileno (Antofagasta, II Región), llamó la atención el aislamiento de levaduras negras (3 veces en baja cantidad), desde estanques con cultivos comerciales de larvas de Argopecten purpuratus (Ostión del Norte) y a veces desde las mismas larvas. La temperatura del agua en la época de muestreo fluctuó entre los $20-21^{\circ} \mathrm{C}$.

Los aislamientos se obtuvieron en cultivos en agar Sabouraud dextrosa $(2 \% \mathrm{NaCl})$, incubados durante $4-5$ dias a $27^{\circ} \mathrm{C}$.

\section{Estudios morfológicos}

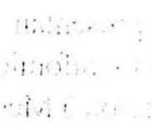

A partir de los 2 primeros aislamientos conservados a baja temperatura $\left(4^{\circ} \mathrm{C}\right)$, se seleccionaron 4 cepas al azar que se sembraron en 3 medios de cultivo a $27^{\circ} \mathrm{C}$ durante 4 semanas: agar Sabouraud dextrosa (2\%), agar Malta y agar Papa dextrosa. Cada 4 días, mediante preparaciones entre lámina y laminilla, se observaron (sin fines comparativos) sus características macroscópicas (lupa estereoscópica) y microscópicas (contraste de fase y óptica normal).

Como liquido montante se empleó lactofenol sólo o con azúl de algodón.

\section{Fisiología}

Los patrones nutricionales de las 4 cepas se efectuaron en galeras de ID $32 \mathrm{C}$ (API) BioMerieux, incubadas durante 7 dias a $28^{\circ} \mathrm{C}$ (de Hooget al, 1992). La producción de ureasa se estudió en agar urea de Christensen, la osmotolerancia $\left(10 \% \mathrm{NaCl}\right.$ y $10 \% \mathrm{MgCl}_{2}$ ) en agar Malta a $28^{\circ} \mathrm{C}$, durante 5 dias y los rangos de tolerancia a la temperatura se efectuaron en agar Malta a $40^{\circ} \mathrm{C}$ durante 7 días.

\section{RESULTADOS}

\section{Macromorfología.}

En los 3 medios de cultivo a $27^{\circ} \mathrm{C}$, las colonias presentaron un aspecto netamente levaduriforme; lisas, brillantes, con márgenes enteros, solevantadas, con un diámetro que osciló entre 8-16 $\mu \mathrm{m}$ en 7 días, olivaceas a negras en el tiempo, reverso del mismo color del anverso. A las 3-4 semanas de crecimiento se apreció en agar Malta y Sabouraud (más que en Papa dextrosa), algunas colonias levaduriformes que presentaron, hifas aéreas, laxas, cortas, poco agregadas, finas, de un tono café intenso.

En agar Malta $(10 \% \mathrm{Mg} \mathrm{Cl})$, a $27^{\circ} \mathrm{C}$, entre las 3-4 semanas de incubación, algunas colonias levaduriformes presentaron en su reverso abudantes hifas negras sumergidas (como pseudomicelio) y escasas hifas áereas cortas en sus superficies. En agar Malta $(10 \% \mathrm{Na} \mathrm{Cl})$ a $27^{\circ} \mathrm{C}$, se obsevó la misma situación pero en menor cantidad.

\section{Micromorfología.}

Células levaduriformes unicelulares y bicelulares, primariamente de paredes finas, subhialinas, posteriormente de pared más gruesa y de color oscuro, subglobosas, elípticas a clavadas. Las bicelulares presentaron un septo que constriñe la parte central. Las unicelulares 7-8 × 3-3,5 $\mu \mathrm{m}$ y las bicelulares $8,5-13 \times 3,5-4 \mu \mathrm{m}$. Células conidiógenas no diferenciadas, apicales o laterales, uni o bipolares, conspicuas, con anélides que se alargan en el tiempo por depósitos de pared (Fig. 1). Conidios unicelulares, percurrentes, pero también que nacen en forma simpodial, uni omultilaterales $(6-8 \times 3-3,5 \mu \mathrm{m})$; los bicelulares $(8-11 \times 3,5-$ $4,5 \mu \mathrm{m})$, en el tiempo, adquieren las dimensiones de las células levaduriformes adultas (Fig.2-3-4). Después de 2 
semanas de incubación, se observó la presencia de células más grandes (clamidosporas) de coloración café oscuro, que germinan por rotura de su pared, liberando endoconidios por alargamiento meristemático (Fig. 7-8).

Hifas dematiáceas escasas en los cultivos jóvenes, pero más visibles en cutivos viejos (Malta y Sabouraud), 4,5-6 $\mu \mathrm{m}$ de ancho, septadas, de gruesas paredes de color oliva a café oscuro, estructuras aneladas conspicuas, anchas en su base 1,5-2,5 $\mu \mathrm{m}$, que se originan en células conidiógenas intercalares o laterales, formando conidios percurrentes o en forma simpodial (Fig. 5-6), al igual que las células levaduriformes y con medidas semejantes. Presencia de escasos racimos de clamidosporas.

\section{Patrones nutricionales y fisiológicos.}

El patrón fisiológico y nutricional de las cepas estudiadas se presenta en Tabla 1; todas las cepas crecieron antes de los 3 días en: glucosa, galactosa, actidione, saca-

Tabla 1. Patrones nutricionales y fisiológicos de H. werneckii (ID 32C), a $27^{\circ} \mathrm{C}$ durante 7 días

\begin{tabular}{|c|c|}
\hline & + \\
\hline Galactosa & + \\
\hline Sacarosa-sucrosa & + \\
\hline Nacetil glucosamina & - \\
\hline Lactato & - \\
\hline Arabinosa & + \\
\hline Celobiosa & + \\
\hline Rafinosa & + \\
\hline Maltosa & + \\
\hline Trehalosa & + \\
\hline 2 Cetogluconato & + \\
\hline Alfa metil D glucosidasa & - \\
\hline Manitol & + \\
\hline Lactosa & + \\
\hline Inositol & + \\
\hline Sorbitol & + \\
\hline Xilosa & + \\
\hline Ribosa & + \\
\hline Glicerol & + \\
\hline Ramosa & + \\
\hline Palatinosa & + \\
\hline Eritritol & + \\
\hline Melobiosa & + \\
\hline Glucoronato & + \\
\hline Melizitosa & + \\
\hline Gluconato & + \\
\hline Levulinato & - \\
\hline Sorbosa & + \\
\hline Glucosamina & - \\
\hline Esculina & + \\
\hline Cicloheximida & $+1-$ \\
\hline $\begin{array}{ll}10 \% \mathrm{NaCl} & + \\
10 \% \mathrm{MaCl} & +\end{array}$ & niento a $30^{\circ} \mathrm{C}$ \\
\hline $\begin{array}{ll}10 \% \mathrm{MgCl} & + \\
\text { Ureasa } & +\end{array}$ & niento a $40^{\circ} \mathrm{C}$ \\
\hline
\end{tabular}

rosa, arabinosa, rátinosa, manitol, inositol, xilosa, glicerol, ramosa, palatinosa, eritritol, melobiosa y ureasa, y con más lentitud en los restantes compuestos mencionados en Tabla 1. La actidiona presente en las galeras del ID $32 \mathrm{C}$, inhibió parcialmente el crecimiento de las cepas, sin embargo todas crecieron en agar Malta con $10 \% \mathrm{NaCl}$ o con $10 \%$ de $\mathrm{MgCl}_{2}$.

\section{DISCUSION}

Las levaduras negras con pared bilamelar y con un poro simplecomunmente delineado con cuerpos de Woronin, son consideradas como anamorfos de Ascomycetes. Su variada conidiogénesis, es fuertemente influenciada por las condiciones de laboratorio o del medio ambiente exógeno (DeHoog, 1993), peroprincipalmente exhiben el tipoblástico (fiálidico o anelidico). En estos microorganismos, el tipo dominate de conidiogénesis se considera la característica principal para delimitar el taxon anamorfo (Cole, 1978; Gams, 1982), sin embargo, el grupo presenta dificultades para una buena determinación taxonómica, las cuales se acentuan por el empleo de medios no estandarizados (Haase et al., 1995).

El ciclo de vida observado durante las 4 semanas de incubación de $H$. werneckii, diliere levemente de lo descrito en la literatura (de Hoog, 1995, De Hoog \& Gerrits van der Ende, 1992). En los medios sólidos empleados, detectamos preferentemente un microciclo higrofilico con colonias siempre levadurilormes, olivaceas a negras y con una fase inicial de células uni y bicelulares. Sus células conidiógenas presentaron sucesivas gemaciones polares o intercalares, con anelaciones bien visibles y variables en cantidad y grosor (dependiendo de los días de incubación) y similares a los observadosen varias especies de Exophiala y otros Hyphomycetes anelidicos.

Nos llamó la atención el frecuente patrón conidiogénico de proliferación simpodial anelidica en muchas células levaduriformes y en las hifas, generalmente del tipo monopolar, una situación que parece ser cepa dependiente (De Hoog \& Gerrits var der Ende, 1992).

Cuando Nishimura \& Miyaji (1984), propusieron el género Hortuea para incluir Exophiala werneckii, se basaron en una cepa única (CBS 107.67), describiendo sus caracteristicas morfológicas al microscopio electrónico de barrido, principalmente por haber observado en las hifas, células conidiógenas (anélides) con proliferación simpodial y células hijas que nacen en forma espiralada, un proceso que tambićn observaron Cole (1978) y De Hoog \& Gerrits van der Ende (1992), bajo el nombre de conidiogénesis simpodial.

McGinnis et al. (1985), Dixon \& Polak-Wyss (1991) y Mittag (1993), analizando la especie tipo del género, no 
encontraron células con desarollo simpodial, sino una conidiogénesis estrictamente anelídica, recalcando los primeros autores, que Nishimura \& Miyaji (1984), no examinaron la especie tipo para conlimmar que su nuevo género contenia las estructuras por ellos descritas. Debe resaltarse, que todas nuestras cepas presentaron ambos tipos de conidiogénesis, donde la proliferación simpodial se observó frecuentemente a lo largo de las 4 semanas de incubación.

El comportamiento de nuestras cepas fue principalmente levaduriforme en las primeras 3 semanas (más que micelial), con la sola presencia de algunas pseudohifas o pequeños conjuntos de hifas a medida que los cultivos envejecian, lo cual es comparable a lo descrito en la literatura. Este ciclo mayoritariamente blástico, presentó una dominante conidiogénesis anelidica, que McGinnis et al. (1985), reconocen bajoel género anamórlicode Phaeanellomyces (P.werneckii), dentro de la Familia Phaeococcomycetaceae, que incluye también los representantes del género Phaeococcomyces de Hoog.

A medida que los cultivos envejecían, algunas células maternas, de aspecto ovoide, engrosaron sus paredes celulares, cesaron en su conidiogénesis anelídica y mediante maduración meristemática y rotura de su pared, liberaron endoconidios lisos. Este tipo de conidiogénesis endógena se relaciona con el género anamórlico de Phaeoteca Sigler et al. (1981).

Se ha observado que algunas cepas pueden producir otros sinanamorfos, como cuerpos esclerotiales multicelulares (tipo Phaeosclera, Sigler et al.,1981). Nuestras cepas presentaron pocas de estas caracteristicas morfológicas en el tiempo de observación.

A pesar que los test fisiológicos son una buena ayuda en la determinación de las especies, necesitan mucho tiempo, pudiendo ser de mayor utilidad si fueran más completos y específicos. Además existen bastantes discrepancias en los resultados de estas pruebas en la literatura, situación que de Hoog et al. (1992), relacionan con el empleo de medios sólidos.

Como ejemplo, algunas de las delimitaciones principales entre $H$. werneckii y Exophiala dermatitidis, se deben al crecimiento $(+)$ de la primera en : lactosa, nitrato, $10 \% \mathrm{NaCl}_{\text {y }} \mathrm{MgCl}_{2}$, y.(-) a temperaturas de $40^{\circ} \mathrm{C}$.

Recientemente en la taxonomía füngica, se están utilizandotécnicasmoleculares (Bruns et al.,1991; McGinnis et al., 1992), pero no existen aún muchos estudios en las levaduras negras (Haase et al., 1995; Masclaux et al., 1995. La mayoría están basados en las secuencias parciales de SSU oLS rRNA y confirman la relación entre varias especies anamórficas (Exophiala, Phaeococcomyces, Phaeoanellomyces, Phialophora, Sarcinomyces), con las Herpotrichiellaceae (y la relación de alguna de éstas con su teleomor to en Capronia)

Recientemente Masclaux et al.(1995), comparando filogeneticamente las secuencias parciales (Ls rRNA), de 42 cepas de hongos y levaduras dematiáceas, con especies patógenas de Cladosporium (Xylohypha), pudieron constatar la existencia de 2 grupos monofiléticos distintos (I y II). El grupo I, contenía todas las especies patógenas humanas de Cladosporium (actualmente incluidos dentro del género Cladophialophora y Exophiala con teleomorfos en Capronia), mientras el grupo II, contenía especies saprofiticas de Cladosporium, junto con Mycosphaerella tassiana, que probablemente son anamorfos de los miembros de las Mycosphaerellaceae, demostrandose la distancia filogenética de cada grupo. Sin embargo, un pequeño número de especies se excluyeron de estos 2 grupos y entre ellas, Aureobasidium pullulans, Hortaea werneckii y las especies de Xilohypha, que se alejan de las otras levaduras negras clasilicadas en Exophiala. Cuando es posible reconocer sus teleomorfos, la mayoría se incluyen en los Dothideales; Exophiala (Herpotrichiellaceae), Hormonema, Aureobasidium (Dothideaceae), pero las cepas de $\boldsymbol{H}$. werneckii, parecen no tener reproducción sexual o simplemente han perdido la capacidad de intercambiar material genético (Uijthof et al., 1994).

Uijthof et al. (1994), mediante PCR de DNA nuclear y mitocondrial, analizaron la estructura poblacional de diferentes cepas de H.werneckii obtenidas de fuentes humanas y otros ambientes naturales. Pudieron delimitar 6 subgrupos y observar que las cepas humanas no se agrupaban entre si como se esperaba, pero se distribuian al azar entre 2 grupos de poblaciones que contenían cepas de otros ambientes. Concluyeron que, las inlecciones en humanos por H.werneckii, se deben a las semejanzas de los nichos ecológicos naturales de esta especie, con la superlicie salada de la palma de las manos, más que a una adaptación del hongo a un nuevo ambiente. Parece ser que el factor homólogo en ambos ambientes, debe correlacionarse con los niveles de $\mathrm{NaCl}$, la sequedad intermitente y el crecimiento a to alrededor de $30^{\circ} \mathrm{C}$. (De Cook, 1994).

\section{CONCLUSIONES}

Nuestras cepas a pesar de su polimorfismo, presentaron las características del género Hortaea y la de varios sinanamorfos (Phaeoanellomyces y Phaeotheca), manteniendo un ciclo predominantemente hidrofílico más que hidrolöbico. La presencia de micelio se presentó generalmente en los cultivos más viejos, pero también en fases más tempranas, sin alterar mayormente el aspecto levaduriforme de las colonias.

Basandonos en las características morfológicas y fisiológicas de nuestras cepas, con una constante conidiogénesis anclídica, proliferación simpodial y un moderado 


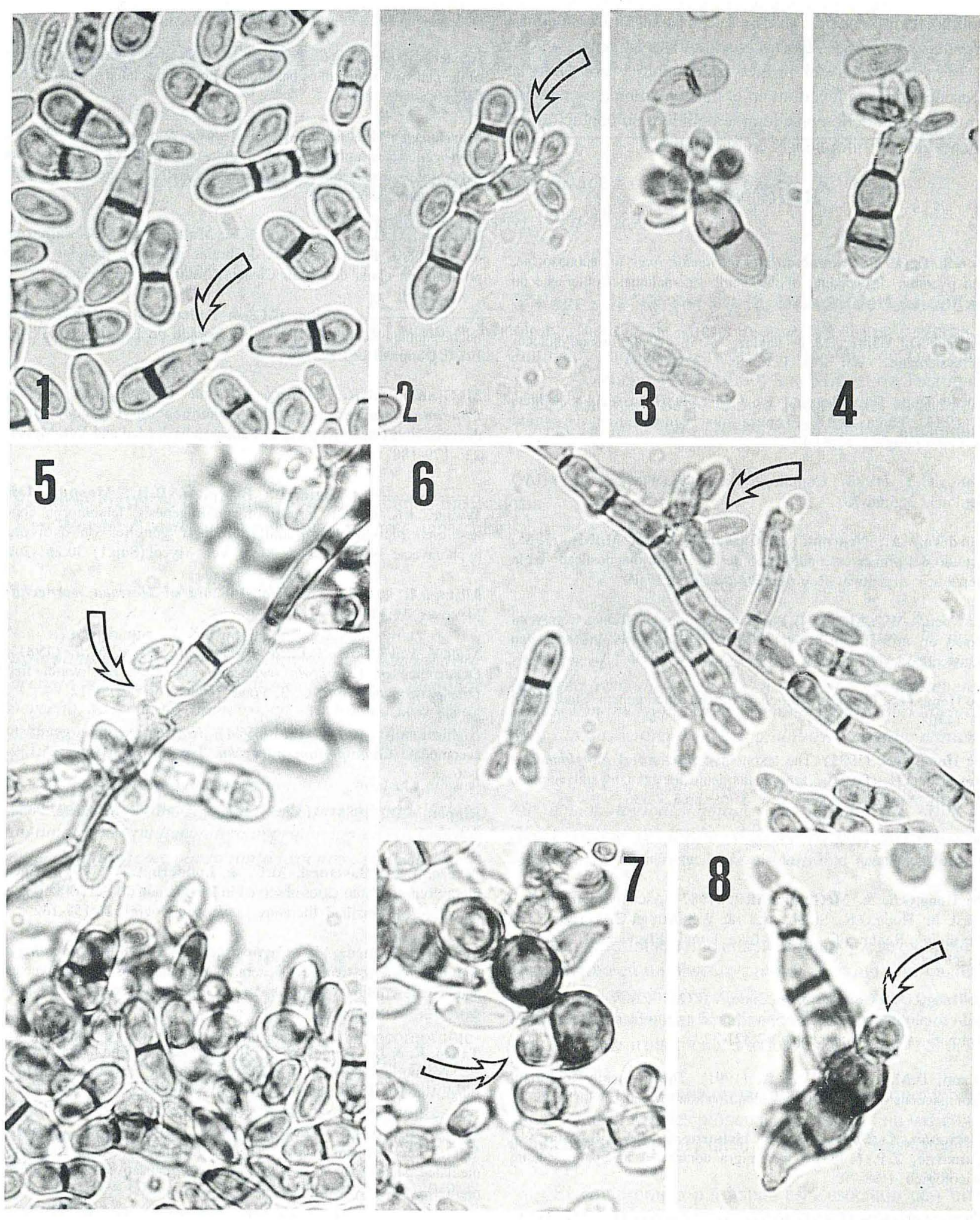

Figura 1 al 8. Hortaea werneckii. 1.- Células levaduriformes uni y bicelulares con anelaciones conspicuas. 2.-3-4. Conidiogénesis simpodial unilateral. 5-6.- Hifas septadas y células conidiógenas. 7-8.- Clamidosporas de paredes gruesas y endoconidios. 
polimorfismo, consideramos a nuestros aislamientos como Hortaea werneckii (Horta) Nishimura \& Miyaji.

Se destaca el primer aislamiento y por ende la presencia de esta levadura en el país en ambientes salinos, situación que debe considerarse debido a su condición de agente de faeohifomicosis en el hombre.

\section{RERENCIAS}

Borelli, D. (1977). Aureobasidium werneckii: Acervuli, sporodochia, and pycnidia. Proceeding of the fourth International Conference on the Mycoses PHAO Sci. Publ. N 356, pp79-90

Bruns,T.D.; White, T.J. \& Taylor, J.A.W. (1991). Fungal molecular systematics. Ann. Rev. Ecol. Syst. 22:525-564

Conti- Diaz, I.A.; Burgoa, F,; Civila, E.;Bonasse,J. \& Miller, A.(1984) Tinea nigra. Primera observación en el Uruguay. Mycopathologia 87:81-83

Cole,, G.T. (1978). Conidiogénesis in the black yeast. PHAO Sci.Publ. 356:66-78

Cordero,A.A.; Negroni, R.; Casa,J.G. Costa, M.E.R. (1985) Estudio del primer caso autóctono de tinea nigra diagnosticado en la República Argentina. Rev. Argent. Micol. 8:17-19

De Cock,A.W.A.M. (1994). Population biology of Hortaea wernwckii based on mitochondrial DNA restriction patterns. Antonie van Leuwenhock 65: 21-28

De IIoog, G.S. (1977). Rhinocladiella and allied genera. Stud.Mycol $15: 1-40$

De Hoog, G.S. (1985). The taxonomyc structure of Exophiala. In: Howard, D.H. (Ed).The fungi pathogenic for humans and animals. Part BII. Marcell Dekker, New York. pp.327-336

De Hoog, G.S. (1993). Evolution of black yeasts: possible adaptation to the human host. Antonie van Leuwenhoeck 63: 105-109

De IIoog,G.S. \&. McGinnis, M.R. (1987). Ascomycetous black yeast. In: Hoog.G.S., Smith, M.T. \& Weijman, A.C.M. (Eds.) The expanding Realm of Yeast -Like Fungi. Elsevier, Amsterdam. pp.187-199

De Hoog, G.S \& Gerrits van der Ende, A.II.G. (1992). Nutritional pattern and eco-physiology of Hortaed werneckii agent of human tinea nigra. Antonie van Leuwenhoeck 62:321-329

Dixon, D.M.\& Polak-Wyss,A. (1991). The medically important dematiaceous fungi and their identification. Mycoses 34:1-18

Fischman, O.;Soares, E.C.; Alchorne,M.M.A.; Batista, G.; Camargo, Z.P. (1983). Tinea nigra contracted in Spain. Boletín Micológico 1:68-70

Gams,W.(1982). Generic names for synanamorpls'? Mycotaxon $15: 459-464$

Haase, G.; Soontag,L.; Peer ,Y.van de.; Uijthof,J.M.J.; Podbielski,A.\& Melzer-Krick,B. (1995). Phylogenetic analysis of ten black yeast species using nuclear small subunit rRNA gene
sequences.Antonie van Leuwenhoeck 68: 19-33

Kreger van Rij,N..J. \& Veenhuis,MI. (1971). A comparative study of the cell wall structure of basidionycetous and related yeasts. J.Gen. Nicrobiol. 68: 87-95

Masclaux,F. Guého, E.; IIooh ,G.S.de \& Christen,R. (1995). Phylogenetic relationships of human-pathogenic Cladosporium (Aylohipha) species inlerred from partial LsrRNA sequences. J. Med. Vet. Mycol. 33:327-338

Matte de, NI.G.S.; Nascimento, F.F.; Mattede, A.F. \& Palhares, Jr.L. (1986). Flora micótica de praias aceanicas polídas a nao poluidas em clima de verao. Ciencia Cultura 38: 664-671

; Coelho, C.C. \& Palhares, Jr.L.(1988). Tinha negra palmar: Relatp de 4 casos no Estrado do Espirito Santo. An. Bras. Dermatol. 63:379-80

McGinnis, M.R.; Wilcy, A.S. \& Carson, J. (1985). Phaeoanellomyces and the phaeococcomycetaceae, new dematiaceous blastomycete taxa. Sabouraudia J. Med and Vet. Mycol. 23: $179-188$

; Sigler,L.; Bowman, B.II.; Masuda,M.\& Wang,C.J.K. (1992). Impact of conidiogenesis, teleomorph connections, pleomorphism and molecular genetics on evolving hyphomycete systematics. J. Med. Vet. Mycol.(Sup.1) 30:261-269

Mittag, II. (1993). The tine' structure of Hortaea werneckii. Mycoses 36:343-350

Mok, W.Y.; Castelo,F.P. \& Baretto de Silva, M.S. (1981). Occurrence of Exophiala werneckii on salted freshwater fish Osteoglosum bicirrhosum. J. Food Technol. 16: 505-512

Nishimura,K. \& Miyaji,M.(1984). Hortaea, a new genus to accomodate Cludosporium werneckii. Jap. J.Med Mycol. 25:139146

Rippon, J.W. (1988). Medical Mycology. 3rd Ed. Saunders, Philadelphia.

Severo, L.C.; Bassanesi, M.C. \& Londero,A.T. (1994). Tinea nigra: Report of four cases observed in Rio Grande do Sul (Brazil) and a review of Brazilian literature. Mycopathologia 126:157-162.

Sigler,L.; Tsuneda,A.\& Carmichael,J.W. (1981). Phaeotheca and Phaeosclera, two new genera of dematiaceous Hyphomycetes and a redescription of Scrcinomyces Lindner. Mycotaxon 12:449467

Takeo, K. \& De IIoog, G.S. (1991). Kariology and hiphal characters as taxonomic criteria in ascomycetous black yeasts and related fungi.Antonie van Leuwenhoeck 60:35-42

Uijthof,J.M.J.; de Cook,A.W.A.M.;de IIooh,G.S.; Quint, W.G.V. \& Belkum,A.van. (1994). Polymerase chain reactionmediated genotyping of Hortuea werneckii, causative agent of tinea nigra. Mycoses 37:307-321 